\title{
EDUCAÇÃO JURÍDICA E CURRÍCULO: UM OLHAR SOBRE A INTERDISCIPLINARIDADE
}

\author{
Carina Deolinda da Silva Lopes ${ }^{1}$
} Franceli B. Grigoletto Papalia ${ }^{2}$

"O espaço interdisciplinar, não pode ser outro senão o campo unitário do conhecimento. Jamais esse espeço poderá ser constituído pela simples adição de todas as especialidades, nem tampouco por uma síntese de ordem filosófica dos saberes especializados. O fundamento do espaço interdisciplinar deverá ser procurado na negação e na superação das fronteiras disciplinares.". Hilton Jaiassu

Resumo: O estudo é uma análise sobre a educação jurídica e o currículo dos Cursos de Direito frente a obrigatoriedade da implementação da interdisciplinaridade em suas disciplinas. As novas diretrizes curriculares dos Cursos de Direito, Resolução n. 5/2018, determina que a aplicação e descrição de como ocorrerá a inclusão da interdisciplinaridade no curso deve ser feito em seu projeto pedagógico. O artigo irá analisar a forma como a interdisciplinaridade será realizada junto aos cursos de direitos, bem como a sua interferência na educação jurídica e no currículo, tendo em vista de que como se conduzirá a construção entre os envolvidos na produção do conhecimento, a fim de sejam para além dos documentos e estes possuam efetividade, ao estarem todos os documentos educacionais conectados em uma mesma sintonia. Para tanto, será utilizado o método indutivo e a técnica é a teórica conceitual, abordagem de alguns conceitos, tais como interdisciplinaridade, educação jurídica e currículo.

Palavras-chave: Cursos de Direito; Currículo; Interdisciplinaridade.

\section{LEGAL EDUCATION AND CURRICULUM: A LOOK AT INTERDISCIPLINARITY}

Abstract: The study is an analysis of legal education and the curriculum of Law Courses in view of the mandatory implementation of interdisciplinarity in their disciplines. The new curricular guidelines for the Law Courses, Resolution n. 5/2018, determines that the application and description of how the inclusion of interdisciplinarity in the course will occur must be done in its pedagogical project. The article will analyze how interdisciplinarity will be carried out in law courses, as well as its interference in legal education and the curriculum, bearing in mind that how the construction among those involved in the production of knowledge will be conducted, in order to go beyond the documents and these have

\footnotetext{
${ }^{1}$ Advogada, docente, mediadora de conflitos em formação (AJURIS; TJ SC), Doutoranda em Direitos Humanos (UNIJUI), bolsista Capes, mestre em direito (URI/SAN), especialista em direito processual civil (ULBRA), direito constitucional (UNISUL), e-mail: lopesdeo@ hotmail.com.

${ }^{2}$ Advogada Especialista em Direito Processual Civil e Previdenciário, Juíza Leiga junto à Comarca de Faxinal do Soturno - TJRS, Doutoranda em Educação pela UFPel, Mestre em Educação pela UFSM, e-mail: franpapalia@gmail.com.
}

Revista de Pesquisa e Educação Jurídica | e-ISSN: 2525-9636 | Encontro Virtual | v. 7 | n. 2 |

p. 92 - 106 | Jul/Dez. 2021. 
effectiveness, as all educational documents are connected in the same harmony. For that, the inductive method will be used and the technique is the conceptual theoretical approach, approaching some concepts, such as interdisciplinarity, legal education and curriculum.

Keywords: Law Courses; Resume; Interdisciplinarity.

\section{Introdução}

O curso de Direito tem sido debate dos especialistas e dos órgãos de classe a muitos anos, especialmente no que tange ao ensino jurídico. O curso de direito é um dos cursos mais procurados junto às instituições de ensino superior e os profissionais que trabalham na docência destes, devem buscar oferecer um Curso voltado para as práticas e exigências do mercado de trabalho, mas também para a formação de um ser humano sensíveis aos anseios da justiça.

O interesse pela temática surge em decorrência das análises realizadas sobre os projetos pedagógicos e o ensino jurídico, frente as novas diretrizes curriculares para o Curso de Direito no Brasil. A publicação da Resolução MEC n. 05/2018 trouxe inúmeras alterações, as quais avolumaram mudanças no ensino jurídico, exemplos disso é a interdisciplinaridade, a prática aliada a teoria, as clinicas jurídicas, entre outros. É neste passo, que se observa a preocupação das alterações trazidas, a qual é fundamental para qualquer estudante, pesquisador, trabalhador ou docente envolvido na área jurídica, tendo em vista a maior preocupação com o futuro dos cursos de direito, especialmente, no que tange o seu desenvolvimento, crescimento e efetiva qualidade da formação dos novos profissionais da área de forma a englobar conceitos como interdisciplinaridade, humanização e a capacidade de mediar e conciliar, em primeiro lugar, antes mesmos de enfrentar longos e doloridos processos judiciais.

No entanto, quando da realização dos estudos dos projetos pedagógicos e das novas diretrizes curriculares nacionais para os Cursos de Diretos, observou-se que a Resolução MEC 05/2018 determinou em seu artigo $2^{\circ}$, parágrafo $1^{\circ}$, inciso $\mathrm{V}$, que a interdisciplinaridade deveria ser um dos elementos estruturais do projeto pedagógico, bem como deveria ainda constar quais as formas em que isso seria inserido e efetivado junto aos cursos. É certo que isso está estreitamente ligado ao currículo do curso, uma vez que a efetivação deste determinação inferirá na forma em que serão dispostas as disciplinas. 
A interdisciplinaridade segundo a Lei de Diretrizes e Bases se estabelece a partir da relação entre duas ou mais disciplinas ou ramos do conhecimento (BRASIL, 1996), o que anteriormente ao disposto na Resolução MEC 05/2018, apesar de já ter previsão nas anteriores diretrizes curriculares do curso, não era efetivado junto ao ensino jurídico.

O ensino jurídico, geralmente, é realizado em caixas e estanques entre si. Mas, a partir da construção de um eixo interdisciplinar no ensino jurídico poderão seus efeitos influenciarem na realização do trabalho dos professores, pois não se pode deixar de considerar a necessidade de mudanças significativas neste área de conhecimento.

Para tanto, na busca pela resposta, será utilizada na presente pesquisa o método indutivo e a técnica é a teórica conceitual, apresentando os estudos de pesquisa bibliográfica, evidenciando também o conhecimento das pesquisadoras. O método científico se pauta no hipotético-dedutivo, o qual analisa a questão problema, hipóteses e teses, a fim de fomentar conclusões.

\section{Interdisciplinaridade e currículo: Resolução MEC 05/2018 e projeto pedagógico}

No processo de implementação das reformas no âmbito da educação, retirando o monopólio estatal no que se refere à legislação que rege as escolas, foi permitido às mesmas que elaborarem suas propostas pedagógicas com maior autonomia e atendendo à realidade na qual enfrentam todos os dias na produção do conhecimento.

O Projeto Pedagógico acompanhou as modificações educacionais, e tem origem na década 1980, momento em que o Brasil passava por profundas reformas. Nessa época, os governos de oposição, aos poucos, foram descrevendo uma política educacional diferente da que estava sendo imposta pelos governos militares. A Constituição Federal de 1988 disciplinou legalmente o PP a fim de dar autonomia às Instituições de Ensino Superior, quanto à elaboração da própria identidade.

A Lei de Diretrizes e Bases da Educação (LDB), Lei n. 9394/96, foi o marco inicial do Projeto Político Pedagógico, o qual fortaleceu a elaboração de projetos diferenciados de acordo com perspectivas e anseios de cada instituição. O artigo 12 da LDB, em seu inciso I, prevê que "os estabelecimentos de ensino, respeitadas as normas comuns e as do seu sistema de ensino, terão a incumbência de elaborar e executar sua proposta pedagógica" (BRASIL, 1996). 
O projeto pedagógico torna-se objeto prioritário de estudo e de discussão. Este tem por objetivo a construção coletiva baseada na análise atenta e concentrada, para interagir com o ambiente em que está inserido, a fim de orientar as ações pedagógicas de forma coesa e crítica.

\begin{abstract}
A construção do projeto político-pedagógico nasce da própria realidade do curso/instituição, tendo como suporte a explicitação das causas dos problemas e das situações nas quais tais problemas aparecem. Deve ser exeqüível e prever as condições necessárias ao desenvolvimento e à avaliação. É necessário que seja uma ação articulada por todos os envolvidos com a realidade do curso/instituição e, também, ser construído continuamente como produto e como processo. (STOCCO, 2011, p.3)
\end{abstract}

A elaboração do Projeto Pedagógico do curso não está relacionada apenas às questões pedagógicas que o envolve, mas com todos os envolvidos no processo da produção do conhecimento. Assim, para que o mesmo não seja apenas um documento sem aplicabilidade, é importante que se adote uma postura cuidadosa para a elaboração de um Projeto Pedagógico, a fim de que este se torne o norte para o curso.

Para tanto, a equipe responsável pela gestão deve procurar atuar de maneira democrática neste processo, a fim de agregar a sociedade no ambiente educacional, sem deixar de respeitas as suas referências basilares. Stürmer e Ferreira (2010) referem que "A gestão democrática é uma forma contemporânea de administração educacional que seduz pelas suas promessas de igualdade e solidariedade na escola, integração escola-comunidade, dentre outras" (STÜRMER, FERREIRA, 2010, p. 156).

No Ensino Superior, da mesma forma, o Projeto Pedagógico é desenvolvido a fim de caracterizar as estratégias do curso, as suas características, objetivos, formas de ação, currículo, disciplinas, bem como a forma que todas estas decisões e planejamentos serão aplicados e construídos entre os professores e acadêmicos para melhor atender os anseios daqueles que fazem parte da instituição. Como explica Rodrigues,

O projeto pedagógico constitui-se no planejamento que um IES faz para um determinado curso. Nele, além de conteúdos e competências, distribuídos nas disciplinas ou módulos e nas atividades que compõem o currículo pleno, é necessário indicar também como serão trabalhados, efetivamente, durante o desenvolvimento do curso, os diversos componentes curriculares. (RODRIGUES, 2020, p. 26) 
É importante que se faça valer o Projeto Pedagógico do curso, a fim de que o mesmo deixe de ser apenas documento do e sobre o curso, com poucas menções de como ele efetivamente pode ser administrado pedagogicamente para que atinja os seus objetivos (RODRIGUES, 2020, p. 26). No ensino superior, o Projeto Pedagógico delimita quais os objetivos do curso, o perfil dos profissionais, carga horária, aulas práticas, disciplinas obrigatórias, entre outros. O projeto pedagógico é o documento que identifica o curso, o qual contém estratégias, métodos, metodologias, técnicas, recursos e instrumentos com relação a como será a forma de atuação para a formação do acadêmico. Como já referido, o mesmo não é apenas um documento de operacionalização do Curso. Neste viés,

Não basta mais listar um conjunto de características e capacidades as quais o futuro profissional deverá ter incorporado ao final. É preciso demonstrar como o curso fará para que elas, de fato, sejam agregadas ao património pessoal do egresso. (RODRIGUES, 2020, p. 52)

Assim, o projeto pedagógico é a orientação do Curso. Como tal, não pode conter somente questões técnicas do curso, mas deve regulamentar as formas como será o ensino, as características dos egressos, as metodologias que serão aplicadas para a produção do conhecimento, entre outras especificações que caracterizem e regulamentem o Curso. Ou seja, o projeto pedagógico faz parte no dia-a-dia da instituição, a fim de que a educação e o conhecimento possam ser produzidos, inovados, melhorados e alcançados, a fim de chegar aos objetivos traçados nestes documentos.

Está é a proposta das últimas e mais atuais diretrizes curriculares nacionais, dispostas através da Resolução MEC 5/2018, a qual, depois longos anos de estudos por diferente segmentos da área jurídica e entidades representativas das categorias, elaborou-se o referido documento que busca trazer transformações no ensino jurídico brasileiro, abarcando não somente a formação do discente, mas também a realização do trabalho do professor, através de novas disciplinas, metodologias e estratégias de ensino.

Rodrigues assim discorre:

Já os professores, na sua maioria, são mal preparados, possuindo apenas a graduação e exercendo o magistério ou como forma de obter "status", que os auxiliará na sua real profissão de advogado, juiz ou promotor, ou como forma de complementar a renda. Como consequiência, não vivem a realidade acadêmica e não se dedicam à pesquisa, restringindo-se a reproduzir em sala de aula as velhas lições de seu tempo de estudantes somadas à sua prática na atividade profissional. (ROGRIGUES, 1988, p. 84) 
Assim, quando nos pautamos nas alterações legislativas e curriculares, não podemos nos despir da figura dos professores nestes processos evolutivos e interdisciplinares, uma vez que estes estão intimamente relacionados a efetivação de tais mudança, a fim de que os acadêmicos que ingressam no mercado de trabalho tenham esse caráter, sendo assim destaca a professora Fatima Aparecida Kian:

Disciplinar, gerando então ensino por grupos de disciplinas que se completam e não
se interagem, em contrapartida Bobbio (1995) já dizia a necessidade do estudo
interdisciplinar do direito, vez que não se pode negar a relevância social dentro de
um contexto nas diversas áreas do conhecimento. Os cursos jurídicos brasileiros
mantiveram durante muito tempo preocupação em oferecer maior profissionalização
aos seus educandos e mantiveram muito tempo o um currículo único e rígido
tentando padronizar o ensino no país, no entanto hoje percebe -se que os cursos de
direito no Brasil assumem uma visão introspectiva baseada num modelo tecnocrata,
fechada, erudita e mostrando desinteressada pela realidade brasileira. (KIAN, 2016,
s.p.)

Fica claro que a interdisciplinaridade busca responder a uma necessidade de superar um olhar fragmentado, utilizado em caixas, como nos processos de produção e socialização do conhecimento, caminhando para novas formas de aprendizagem.

Essa questão ecoa também na necessidade de considerar os conhecimentos do homem enquanto ser dialético e vivente de uma realidade social, onde necessitamos levar em consideração vários contextos e problemáticas, sendo fundamental também trazer esta função ampliada para o âmbito escolar, onde o interdisciplinar efetuará uma excelente colaboração no ensinar e no aprender na escolarização formal.

A interdisciplinaridade surge na metade do século passado como forma de superar os aspectos fragmentados e o caráter de especialização do conhecimento, cuja tendência está no empirismo, naturalismo e mecanicismo científico, essa ciência ganha força.

A referida modalidade funciona como uma reação no campo conceitual, como uma alternativa à abordagem disciplinar normalizadora, situada onde se pensa a possibilidade de superar a fragmentação das ciências e dos conhecimentos, possibilitando que haja uma compreensão de que estes se conectam, se interligam.

A interdisciplinaridade está amparada tanto no âmbito pedagógico quanto epistemológico por um conjunto de princípios teóricos formulados a partir de pensadores que 
auxiliam de forma crítica o modelo positivista das ciências e buscam resgatar o caráter, a visão, da totalidade do conhecimento.

Essa forma de perceber o conhecimento está possibilitando o impulsionar e transformações em agir e pensar no ser humano. Dessa forma é entendido o interdisciplinar como um movimento importante para ensinar e aprender, possibilitando auxiliar os educadores e as escolas na ressignificação do trabalho pedagógico em relação ao currículo, métodos, conteúdos, avaliações e até mesmo na forma de organizar o ambiente de aprendizagem escolar.

Neste sentido Gaudêncio Frigotto enfatiza que:

O caráter necessário do trabalho interdisciplinar na produção e na socialização do conhecimento no campo das ciências sociais e no campo educativo que se desenvolve no seu bojo não decorre de uma arbitrariedade racional e abstrata. Decorre da própria forma de o homem produzir-se enquanto ser social e enquanto sujeito e objeto do conhecimento social. Os homens buscam incessantemente de satisfazer suas múltiplas e sempre históricas necessidades de natureza biológica, intelectual, cultural, afetiva e estética estabelecem as mais diversas necessidades. (2011, p. 36)

Esta necessidade de interdisciplinaridade no que tange a produção do conhecimento tem fundamento no caráter dialético da realidade social que possui ao mesmo tempo um modo uno e diverso da realidade intersubjetiva, esse viés nos impõe distinguir os limites reais os sujeitos, mas isso não significa que tenhamos que abandonar ou fragmentar os conhecimentos que se conectam a determinado viés de analise e no caso deste estudo do estudo do Direito.

Assim, em uma sociedade pós-moderna influenciada principalmente pelas múltiplas informações, deve-se ter em mente que é necessário mudar a forma de evidenciar o cenário dos cursos de Direito, de gladiadores para pacificadores, onde os cursos de direito devem estar preocupados também com uma formação integral e humanizada do futuro profissional dos discentes, sendo uma boa prática para tal concretização as atividades interdisciplinares, ainda muito difíceis de serem observadas dentro das áreas que abrange o currículo do Curso de Direito.

Observa-se que a Resolução MEC 05/20018 busca essa formação diferenciada, aliada a formação profissional e científica consistente para que o graduando desenvolva plenamente sua capacidade de interpretação dos fenômenos jurídicos e sócio-institucionais que se lhe 
apresentarão de maneira concreta na convivência social e institucional, de forma interdisciplinar, conforme se observa do artigo $2^{\circ}$ da referida resolução ${ }^{3}$.

Mas a inclusão da interdisciplinaridade na educação não é uma novidade dos Cursos de Direito, a Lei de Diretrizes e Bases já traz tal orientação, a fim de estabelecer no ensino uma inter-relação entre as diversas áreas do conhecimento. Da mesma forma, no Curso de Direito, que desde de Portaria do MEC de 1996, há a previsão da interdisciplinaridade, posteriormente a Resolução MEC 9/2004, mas em nenhuma dela havia a previsão expressa de que deveria ser descrito no projeto pedagógico do curso como seria realizada. É neste sentido, que

\begin{abstract}
A realização efetiva da interdisciplinaridade não ocorre pela simples inclusão, no currículo, de uma série de conteúdo de áreas afins, individualizados em disciplinas específicas. Essa prática propicia apenas um conjunto de visões monodisciplinares do fenômeno jurídico [...] a interdisciplinaridade não se realiza em um conjunto de discursos isolados e estanques, mas sim na análise do objeto a partir de categorias pertencentes aos vários ramos do conhecimento em um mesmo momento, buscando apreender a maior variedade possível de relações e compreensões. (RODRIGUES, 2020, p. 72-73)
\end{abstract}

A interdisciplinaridade funciona como princípio mediador entre as diferentes disciplinas e como um elemento teórico-metodológico da diferença e da criatividade. A interdisciplinaridade é o princípio da máxima exploração das potencialidades de cada ciência,

\footnotetext{
${ }^{3}$ Art. $2^{\circ}$ No Projeto Pedagógico do Curso (PPC) deverão constar:

I - o perfil do graduando;

II - as competências, habilidades e os conteúdos curriculares básicos, exigíveis para uma adequada formação teórica, profissional e prática;

III - a prática jurídica;

IV - as atividades complementares;

V - o sistema de avaliação;

VI - o Trabalho de Curso (TC);

VII - o regime acadêmico de oferta; e

VIII - a duração do curso.

$\S 1^{\circ} \mathrm{O}$ PPC, abrangerá, sem prejuízo de outros, os seguintes elementos estruturais:

I - concepção do seu planejamento estratégico, especificando a missão, a visão e os valores pretendidos pelo curso;

II - concepção e objetivos gerais do curso, contextualizados com relação às suas inserções institucional, política, geográfica e social;

III - condições objetivas de oferta e a vocação do curso;

IV - cargas horárias das atividades didático-formativas e da integralização do curso;

$\mathrm{V}$ - formas de realização de interdisciplinaridade, de mobilidade nacional e internacional, de incentivo aÌ inovação e de outras estratégias de internacionalização, quando pertinente;

[...]
} 
da compreensão dos seus limites, mas, acima de tudo, é o princípio da diversidade e da criatividade (ETGES, 1993, p. 18).

Neste sentido para o direito é fundamental essa construção interdisciplinar haja vista que segundo os autores Maria Cecilia Lorea Leite e Renato Duro Dias, entende-se que:

[...] um dos desafios dos profissionais educadores que operam o Direito como campo do saber seria o de propiciar condições para que o ensino jurídico supere a distância da realidade social, de forma a responder de forma mais efetiva aos desafios postos por um contexto contemporâneo complexo e permeado de novos conflitos. E, mais, que a ciência jurídica esteja apta a possibilitar a formação de um bacharel: crítico, reflexivo e agente de transformação social. (LEITE, DIAS, 2012, p. 5)

A interdisciplinaridade, desta forma, é a mudança de atitude frente a produção do conhecimento, na busca de uma leitura mais abrangente de troca, reciprocidade e comprometimento entre professor, aluno e instituição. Neste passo, o ensino jurídico interdisciplinar trará ao curso de direito o rompimento com o ensino compactado e fragmentado, a fim de realizar uma conversação "permanente entre as disciplinas e troca de conhecimentos, experiências e metodologias, pode potencializar ou inspirar atitudes mais comunicativas, seja entre as disciplinas, entre os eixos curriculares ou entre projetos de extensão ou de pesquisa." (DIAS, 2014, p. 25)

É possível afirmar que a perspectiva integrada de tais enfoques curriculares permanece hoje na concepção de interdisciplinaridade. $\mathrm{Na}$ medida em que as disciplinas escolares têm suas fontes de organização situadas no conhecimento de referência que é pensada a integração. Trata-se de uma concepção de currículo integrado que valoriza as disciplinas individuais e suas inter-relações. Defender a interdisciplinaridade pressupõe considerar a organização disciplinar e, ao mesmo tempo, conceber formas de inter-relacionar as disciplinas a partir de problemas e temas comuns situados nas disciplinas de referência (LOPES, MACEDO, 2011, p. 131)

De acordo com Fazenda (2015), para ter a interdisciplinaridade é preciso que a prática e didática se interliguem, sendo assim, é necessário ter um envolvimento crítico e reflexivo, para ter maturidade e permitir que a interação aconteça, devido a sua complexidade. E, prossegue:

A interdisciplinaridade na formação profissional requer competências relativas às formas de intervenção solicitadas e às condições que concorrerem ao seu melhor exercício. Neste caso, o desenvolvimento das competências 
necessárias requerem a conjugação de diferentes saberes disciplinares sejam de ordem prática e/ou didática. Entenda-se por saberes disciplinares: saberes da experiência, saberes técnicos e saberes teóricos interagindo dinamicamente sem nenhuma linearidade ou hierarquização que subjugue os profissionais participantes (FAZENDA, 2015, p. 14-15)

Para tanto, é necessário definir um conceito para currículo, uma vez que esta é uma pergunta frequente. Neste projeto, utilizará o conceito de currículo por Alice Lopes e Elizabeth Macedo que parecer mais pertinente para este estudo. As autoras referem no capitulo I de sua obra que "os estudos curriculares têm definido currículo de forma muito diversas e várias dessas definições permeiam o que tem sido denominado currículo no cotidiano das escolas" (LOPES, MACEDO, 2011, p. 19), neste passo, continua, e refere que o currículo é "a grade curricular com disciplinas/ atividades, os planos de ensino dos professores, as experiências propostas e vividas pelos alunos" (LOPES; MACEDO, 2011).

Assim, observa-se que o currículo tem relação com o indivíduo, poder, sua transformação e com a sociedade, não se distanciado das questões sociais que permeiam o ensino jurídico e a comunidade em que se está inserida.

Como se observa da Resolução MEC 05/2018, as novas diretrizes curriculares dos cursos de direito determina que o perfil do egressos do curso deve possuir as características do meio social e cultura o qual está inserido, isso não está presente apenas do projeto político e pedagógico do curso, mas no currículo ao qual este irá trazer, tendo em vista que o currículo é um espaço de produção e de política cultural, no qual os conteúdos existentes se encaixam para a formação de acordo com a situação social imposta.

Neste passo, já lecionava Telles Junior (2003)

Durante cinco anos do Curso, matérias muitas e diversas são explicitadas e estudadas. Mas, reparem, todas elas se prendem umas com as outras. Relacionam-se pelos seus primeiros princípios, pelos seus fundamentos, pelos fins que almejam. Em verdade, podemos até dizer que, durante todo o Curso numa Faculdade de Direito, só cuidamos de uma única disciplina: A Disciplina da Convivência Humana (TELLES JUNIOR, 2003, p. 2)

O currículo interdisciplinar no ensino jurídico romperá com o ensino individualizado e em caixa que hoje temos nos cursos de direito, a fim de alcançar o verdadeiro propósito das novas diretrizes curriculares. 
O enfraquecimento de uma percepção global leva ao enfraquecimento do senso de responsabilidade - cada um tende a ser responsável apenas por sua tarefa especializada, bem como ao enfraquecimento da solidariedade - ninguém mais preserva seu elo orgânico com a cidade e seus concidadãos (MORIN, 2001, p. 18)

Resta claro a relação estabelecida a relação entre o currículo do curso o professor,

A relação currículo e Universidade acaba produzindo uma forte ferramenta ideológica, capaz de fornecer subsídios para a formação de um indivíduo pouco preocupado com as questões sociais relacionadas a "operação da justiça", mas, por outro lado, bastante interessado em acumular conhecimento técnico capaz de facilitar seus anseios profissionais imediatos. (STEFAN; LEITE, 2016, p. 24/25)

Assim, a interdisciplinaridade no Curso de Direito buscará assegurar ao seu acadêmico uma formação integral, tanto social, quanto profissional, humana, entre outras, se despindo deste conhecimento divididos em pequenas caixinhas que apenas formam profissionais tecnicistas. É neste sentido que o trabalho dos professores auxiliara na construção destes “novos" profissionais. Rodrigues $(2019$, p. 70) corrobora:

\footnotetext{
Quando as ações docentes são planejadas, evita-se a improvisação e garante-se, através da utilização de estratégias adequadas, uma maior probabilidade de atingir os objetivos propostos. Assim o tempo é melhor utilizado, menos energia é consumida e o trabalho é realizado com maior segurança. Além dos elementos já referidos anteriormente, o planejamento da atividade docente deve partir de um diagnóstico da realidade que considere relativamente a cada componente curricular específico. (RODRIGUES, 2019, p. 70)
}

Assim, evidente é que a efetivação do ensino interdisciplinar, se dará quando houve a interação professor/aluno e professor/professor (FAZENDA, 2003), pois a educação só tem sentido no encontro, na "mutualidade", numa relação em que haja reciprocidade, amizade e respeito mútuo. A interdisciplinaridade exigirá do professor postura diferenciada, conforme cita Fazenda (2003):

O professor interdisciplinar traz em si um gosto especial por conhecer e pesquisar, possui um grau de comprometimento diferenciado para com seus alunos, ousa novas técnicas e procedimentos de ensino. Antes, porém, analisa-os e dosa-os convenientemente.

Neste sentido, é imprescindível que se realize a análise o ensino jurídico e o currículo, partindo da reflexão sobre a interdisciplinaridade aliado ao professor. Nesta direção, analisar as a descrição do ensino jurídico interdisciplinar nos projetos pedagógicos dos Cursos de 
Direito, é buscar resposta de que maneira é estabelecida nos projetos pedagógicos e nos currículos dos cursos.

\section{Conclusão}

Diante das leituras e levantamentos realizados até o momento, verificou-se que o Curso de Direito já está enfrentando mudanças neste cenário do ensino do jurídico, mas com a propagação das práticas pedagógicas, os docentes já estão buscando aperfeiçoamento pedagógico, a fim de direcionar os discentes a terem uma visão global do Curso e ao final alcançarem capacidade de observar seu papel em prol aos anseios sociais.

Buscou-se observar e estudar a interdisciplinaridade nos cursos de direito, sua efetivação no ensino jurídico, no que tange a sua descrição e aplicabilidade no projeto político pedagógico e no currículo.

Assim, o presente estudo busca apresentar a importância do projeto pedagógico do curso de Direito para a realização da interdisciplinaridade, a fim de que haja o envolvimento de toda a comunidade acadêmica, tanto dos docentes, quanto dos discentes e instituição, sendo que é extremamente necessário para a prática do saber que possa sair dos projetos e currículos para alcançar as salas de aula dos cursos jurídicos.

Desta forma, observa-se que é preciso acabar com as fronteiras que não permitem que os estudos jurídicos possam ser analisados de forma compartilhada, interdisciplinar, o que ocorrendo irá dar inicio à formação de profissionais diferenciados e nisso o trabalho pedagógico dos professores é de suma importância, este é o que está buscando do Ministério da Educação com a edição desta Resolução de n. 5/2018, a qual tem como principal objetivo reformular o ensino jurídico no Brasil, para atender os anseios sociais atuais e qualidade educacional.

É preciso buscar formas de efetivar o compartilhamento dos conteúdos e práticas jurídicas que são interligadas, para isso o primeiro passo é movimentar-se no sentido de fomentar ações práticas que concretizem os aspectos curriculares.

\section{Referências bibliográficas}


BRASIL, Presidência da República. Lei n. 9394/96. Dispõe "Estabelece as diretrizes e bases da educação nacional.”. Disponível em

<http://www.planalto.gov.br/ccivil_03/leis/19394.htm>. Acesso em: 02 de novembro de 2019.

DIAS, Renato Duro. Relações de poder e controle no currículo do Curso de Direito da FURG. Tese (Doutorado em Educação) - Programa de Pós-Graduação em Educação. Faculdade Educação. Universidade Federal de Pelotas, 2014. Repositório UFPel. Disponível em http://repositorio.ufpel.edu.br:8080/handle/prefix/3348. Acesso em 25 de julho de 2021.

ETGES, N.J. Produção do conhecimento e interdisciplinaridade. Educação e realidade, v. 18, n. 2, p. 73-82, jul/dez, 1993. Porto Alegre.

FAZENDA, Ivani C. A. Praticas Interdisciplinares na Escola. $3^{\text {a }}$ edição São Paulo, Cortez, 1996 http://www.scribd.com/doc/8552690/Praticas-Interdisciplinares-na-Escola.

FAZENDA, I. C. A. Interdisciplinaridade: Didática e Prática de Ensino. Revista Interdisciplinaridade/Grupo de Estudos e Pesquisa em Interdisciplinaridade (GEPI)Educação: Currículo- Linha de Pesquisa: Interdisciplinaridade. v.1, n.6- especial. p. 9-17. São Paulo: PUCSP, 2015.

FRIGOTTO, Gaudêncio. Interdisciplinaridade como necessidade e como problema nas ciências sociais. In: JANTSCH, Ari Paulo; BIANCHETTI, Lúcio. Interdisciplinaridade. 9. Ed. Petrópolis: Vozes, 2011.

JAPIASSU, Hilton. Interdisciplinaridade e patologia do saber. Rio de Janeiro. Imagio Editora: 1976.

KIAN, Fatima Aparecida. Interdisciplinareidade no Direito e na Educação. Disponível em: https://fatimakian.jusbrasil.com.br/artigos/316025681/interdisciplinaridade-no-direito-e-naeducacao. Acesso em 19/02/2019.

LEITE, Maria Cecilia Lorea; DIAS, Renato Duro. Imagens da justiça e questões de gênero e sexualidade: elementos para a análise do currículo do curso de direito e de sua pedagogia. Disponível em:

http://www.ucs.br/etc/conferencias/index.php/anpedsul/9anpedsul/paper/viewFile/2662/950. Acesso em: 02. Mar. 2021.

LOPES; Alice C.; MACEDO, Elizabeth. Teorias de Currículo. São Paulo: Cortez, 2011.

MINISTÉRIO DA EDUCAÇÃO. Conselho Nacional de Educação. Parecer Homologado 365. Portaria ${ }^{\circ}$ 1.351, publicada no D.O.U. de 17/12/2018, Seção 1, Pág. 34.

<http://portal.mec.gov.br/docman/outubro-2018-pdf-1/100131-pces635-18/file>. Acesso em 08 de novembro de 2019.

MEC. Resolução no 5, de 17 de dezembro de 2018. Disponível em: https://www.in.gov.br/materia/-/asset publisher/Kujrw0TZC2Mb/content/id/55640393/do12018-12-18-resolucao-n-5-de-17-de-dezembro-de-2018-55640113. Acesso em: 04. Set. 2020.

Revista de Pesquisa e Educação Jurídica | e-ISSN: 2525-9636 | Encontro Virtual | v. 7 | n. 2 |

p. $92-106$ | Jul/Dez. 2021. 
MORIN, Edgard. A cabeça bem-feita: repensar a reforma, reformar o pensamento. Trad. Eloá Jacobina. 5. ed. Rio de Janeiro: Bertrand Brasil, 2001.

MOROSINI, Marília da Costa; FERNANDES, Cleoni Maria Barbosa. Estado do

Conhecimento: conceitos, finalidades e interlocuções. Educação Por Escrito, Porto Alegre, v. 5, n. 2, p. 154-164, jul. dez. 2014. Disponível em: http://revistaseletronicas.pucrs.br/ojs/index.php/porescrito/article/view/18875. Acesso em 15 de junho de 2019.

RODRIGUES, Horácio Wanderlei. Ensino Jurídico e Realidade Social. 17 Sequência. UFSC, Florianópolis, SC, Brasil, 1988. Disponível:

<https://periodicos.ufsc.br/index.php/sequencia/issue/view/1535>. Acesso em: 14 de fevereiro de 2021.

RODRIGUES, Horácio Wanderley. Novo currículo mínimo dos cursos jurídico. São Paulo: Revista dos Tribunais, 1995.

RODRIGUES, Horácio Wanderlei. Cursos de Direito no Brasil: diretrizes curriculares e projeto pedagógico. 2. ed. Habitus Editora. Florianópolis: 2020.

STEFAN, Guilherme; LEITE, Maria Cecilia Lorea; A questão social no currículo de direito: uma discussão através de imagens. Coleção Imagens da Justiça, Contemporâneidade, imagens da justiça e ensino jurídico. Organização de Maria Cecília Lorea Leite, José Octavio Van-Dúnem, Ana Clara Correa Henning. - São Leopoldo: Casa Leiria, 2016. Disponível em https://gpaju.paginas.ufsc.br/files/2016/03/Livro-Imagens-da-Justi\%C3\%A7a-v.-01.pdf. Acesso em 20 de março de 2021.

STOCCO, Josete Alzira Passamani. (Re)pensando a construção dos projetos políticopedagógicos de curso de graduação. UPF. Passo Fundo: 2011. Disponível em file:///C:/Users/User/Downloads/1737-Texto\%20do\%20artigo-6561-1-1020110614\%20(1).pdf. Acesso em 18 de março de 2020.

STÜRMER, Arthur Breno Stürmer, FERREIRA, Liliana Soares. A gestão democrática nas escolas públicas de Santa Catarina. Educação, Santa Maria, v. 35, n. 1, p. 155- 168, jan./abr. 2010 Disponível em: https://periodicos.ufsm.br/reveducacao/article/view/1372. Acesso em 27 de junho de 2020.

TELLES JÚNIOR, Goffredo. Palavras do amigo aos estudantes de direito: bosquejos extra-curriculares, proferidos no escritório do professor em 2002. 1. ed. São Paulo: Editora Juarez de Oliveira, 2003.

VEIGA, Ilma Passos da. Projeto político-pedagógico da escola: uma construção coletiva. In: VEIGA, Ilma Passos da (org.). Projeto político-pedagógico da escola: uma construção possível. Campinas: Papirus, 1998. p.11-35. Disponível: <https://www.sinprodf.org.br/wpcontent/uploads/2014/01/PPP-segundo-Ilma-Passos.pdf>. Acesso em 23 de outubro de 2019. 
VEIGA. Ilma Passos Alencastro. Educação Superior: políticas educacionais, currículo e docência. Editora CRV. Curitiba: 2016.

ZIMIANI, D. T.; HOEPPNER, M. G. Interdisciplinaridade no ensino do Direito. In:

Akrópolis Umuarama, v. 16, n. 2, p. 103-107, abr./jun. 2008. Disponível em:

<http://www.revistas.unipar.br/index.php/akropolis/article/download/2302/1890>. Acesso em: 15 de setembro de 2019. 